\title{
Anaplastic lymphoma kinase (ALK) rearrangement in adult renal cell carcinoma with lung metastasis: a case report and literature review
}

\author{
Shengyu Zhou', Guanxing Sun ${ }^{2}$, Jianwei Wang ${ }^{1}$, Hongtu Zhang ${ }^{1}$ \\ ${ }^{1}$ Department of Medical Oncology, National Cancer Center/National Clinical Research Center for Cancer/Cancer Hospital, Chinese Academy of \\ Medical Sciences (CAMS) and Peking Union Medical College (PUMC), Beijing, China; ${ }^{2}$ Department of Medical Oncology, Zaozhuang Municipal \\ Hospital, Zaozhuang, China \\ Correspondence to: Shengyu Zhou. Department of Medical Oncology, National Cancer Center/National Clinical Research Center for \\ Cancer/Cancer Hospital, Chinese Academy of Medical Sciences (CAMS) and Peking Union Medical College (PUMC), Beijing 100021, China. \\ Email: typhoonwho@126.com.
}

\begin{abstract}
Renal cell carcinoma (RCC) with anaplastic lymphoma kinase (ALK) rearrangement is rare, and the genetic profiles of the tumor have not been elucidated. Here, we report a case with recurrent papillary RCC and lung metastasis after nephrectomy for nearly 7 years. The patient first received sunitinib, whereas the drug toxicity was intolerable. Combined Immunohistology (IHC) and fluorescence in situ hybridization (FISH) revealed the patient has an ALK rearrangement, and the patient then was treated with crizotinib. The patient had good tolerance, and a partial response in the target lesions was achieved. In order to further understand the benefit of crizotinib in ALK-rearranged RCC, the patient was detected with whole exome sequencing (WES) to study her genetic profiles. Compared those of RCC cases without ALK rearrangement (nALK-RCC), the patient and nine RCC cases with ALK rearrangement (ALK-RCC) revealed unique genetic characteristics: 1) The common mutations that occurred in RCC were not found in ALK-RCC.; 2) A total of 11 co-existing mutations in ALK-RCC were found, and they occurred in nALK-RCC at a relatively low frequency. DNMT3A mutations were concurrent with ALK fusions in our case. These findings indicated a different genetic alteration pattern of ALK-RCC from nALK-RCC. Our case demonstrated the efficacy of crizotinib in an RCC patient with ALK rearrangement.
\end{abstract}

Keywords: Renal cell carcinoma (RCC); lung metastasis; ALK rearrangement; crizotinib; genomic feature

Submitted Sep 11, 2020. Accepted for publication Dec 16, 2020.

doi: $10.21037 /$ tau-20-1343

View this article at: http://dx.doi.org/10.21037/tau-20-1343

\section{Introduction}

Renal cell carcinoma (RCC) is common solid cancer (1). The most frequent site of metastasis and recurrence is the lung, with more than half of patients developing lung metastases (2,3). Anaplastic lymphoma kinase (ALK) rearrangement has been reported in various tumors, including in anaplastic large cell lymphoma, non-small cell lung cancer (NSCLC), and colonic adenocarcinoma. ALK rearrangements are seen in 3-7\% cases of nonsmall cell lung cancer (NSCLC) (4) and in 2 of 534 (<1\%) RCCs (5).
ALK rearrangement is the most common type with a wide variety of ALK fusion partners having been discovered (3). EML4 is the predominant fusion partner gene of ALK found in lung adenocarcinoma (4 to $7 \%$ of cases), while KIFSB is the second common in frequency (0.5\%) (6). Except EML4 and KIF5B, other fusion partner genes, such as BIRC6 (7), TFG (8), SEC31A (9), HIP1 (10), TPR (11), DCTN1 (12) and KLC1 (13), have been identified as oncogenic events. Currently, ALK inhibitors approved by the National Medical Products Administration (NMPA) 
include crizotinib, and the median progression-free survival with first-line crizotinib is 17.6 months (14). Other clinical trials, including PROFILE 1029 and PROFILE 1014, showed that crizotinib demonstrated significantly improved PFS, ORR, and PROs and had a distinct safety profile that was tolerable and manageable $(15,16)$. Crizotinib improved PFS independent of age, sex, ECOG PS, tumor histological type, and type of platinum-based chemotherapy. However, crizotinib has not been reported for the treatment of renal cell carcinoma complicated by lung metastases.

Detection of ALK rearrangements in patients with non-small cell lung cancer has recently become a routine pathological diagnosis. Several highly efficient therapeutic ALK inhibitors including crizotinib, alectinib, ceritinib and lorlatinib, almost always provide remarkable benefit to the patients. Fluorescence in situ hybridization (FISH), real-time reverse transcription-PCR (RT-PCR), and immunohistochemistry (IHC) (17) are three major conventional diagnostics for ALK fusions. Here, we reported a case for ALK fusions by combining FISH analysis and IHC assay, and collaborative testing with WES revealed the genomic features of ALK-RCC. In addition, the genetic characteristics of ALK-RCC were revealed by comparing its genetic data to that of RCC patients without ALK rearrangement. Based on computed tomography (CT) scan, we aimed to investigate the responsiveness of ALKRCC to crizotinib.

We present the following case in accordance with the CARE reporting checklist (available at http://dx.doi. org/10.21037/tau-20-1343).

\section{Case presentation}

We report a female patient born in 1984, who had a clinical history of renal space-occupying lesion which was discovered by a pregnancy check-up in September 2010, leading to a right nephrectomy in July 2011. Computed tomography (CT) scan and postoperative pathological findings confirmed the morphology of papillary RCC (Figure S1A,B). The patient received interferon $\alpha$ therapy for nearly 6 months. Regular re-examination did not indicate any sign of recurrence in the past few years, except a slight increase in CA125 levels. In August 2018, the CA125 level suddenly elevated to $805.3 \mathrm{U} / \mathrm{mL}$. Subsequent positron emission tomography (PET)-CT revealed retroperitoneal multiple lymphadenopathy with increased metabolism, along with multiple nodules in bilateral lungs with increased metabolism (Figure 1A), which suggested tumor metastases. For this progression, lung biopsy under the CT guidance and subsequent pathological examination were performed. While waiting for the pathological results, the patient started treatment with sunitinib. During the treatment, adverse events, including fever, waist soreness, and hematochezia, in addition to abnormal laboratory results for transaminase, white blood cells, and red blood cells, were observed and deemed intolerable. One month later, a diagnosis of clinical stage IV (TxN0M1) metastatic RCC was made (Figure 1B). The immunohistology (IHC) staining showed tumor cells with positivity for ALK, programmed cell death-ligand 1 (PD-L1), paired box 8 (PAX8), vascular endothelial growth factor 2 (VEGFR2), and tuberous sclerosis 2 (TSC2). The Ki-67 score was $60 \%$. The Ventana IHC (Ventana automated IHC with Ventana ALK-D5F3 detection kit) revealed an ALKpositive result (Figure 1C,D), which was then further confirmed by ALK break-apart FISH where results showed ALK rearrangement (Figure 1E,F). Therefore, starting in November 2018, sunitinib was replaced by crizotinib therapy (250 mg, twice/day). During this treatment, the patient had a very good performance status [Eastern Cooperative Oncology Group (ECOG) 1], and no adverse events were observed. Follow-up CT scans revealed a partial response in October 2019 (Figure 1A). The patient is still under treatment with crizotinib, and a stable disease state was revealed by a CT scan in December 2019 (Figure 1A).

ALK fusion is rare in RCC, and the genomic features remain unclear. To clarify this, whole exome sequencing (WES) was performed, the genetic data of the primary tumor were obtained, and a co-existing gene mutation, DNMT3A, was detected. Due to the limitation of WES, the gene fusions could not be detected effectively, and the ALK fusion partner of the case is unknown. To further explore the incidence of ALK fusion, the mutation data of 276 papillary RCC patients were downloaded from the cBioportal for Cancer Genomic database (https://www. cbioportal.org/). Of the 276 papillary RCC patients, 2 patients also harbored ALK fusions, with 1 carrying ALKEML4, and another carrying STRN-ALK. Moreover, the genetic profiles of the six RCC patients with EML4-ALK fusions reported by Sumanta and his colleagues, seven were added to the ALK-RCC cohort of this study (Table 1). By comparing the mutation data among ALK-RCC and RCC without ALK fusion (nALK-RCC), we found that the most common mutations in nALK-RCC (occurrence rate $>6 \%$ ) were not found in ALK-RCC (Figure 2A). Co-existing mutations in ALK-RCC included DNMT3A, TERT, and 
A

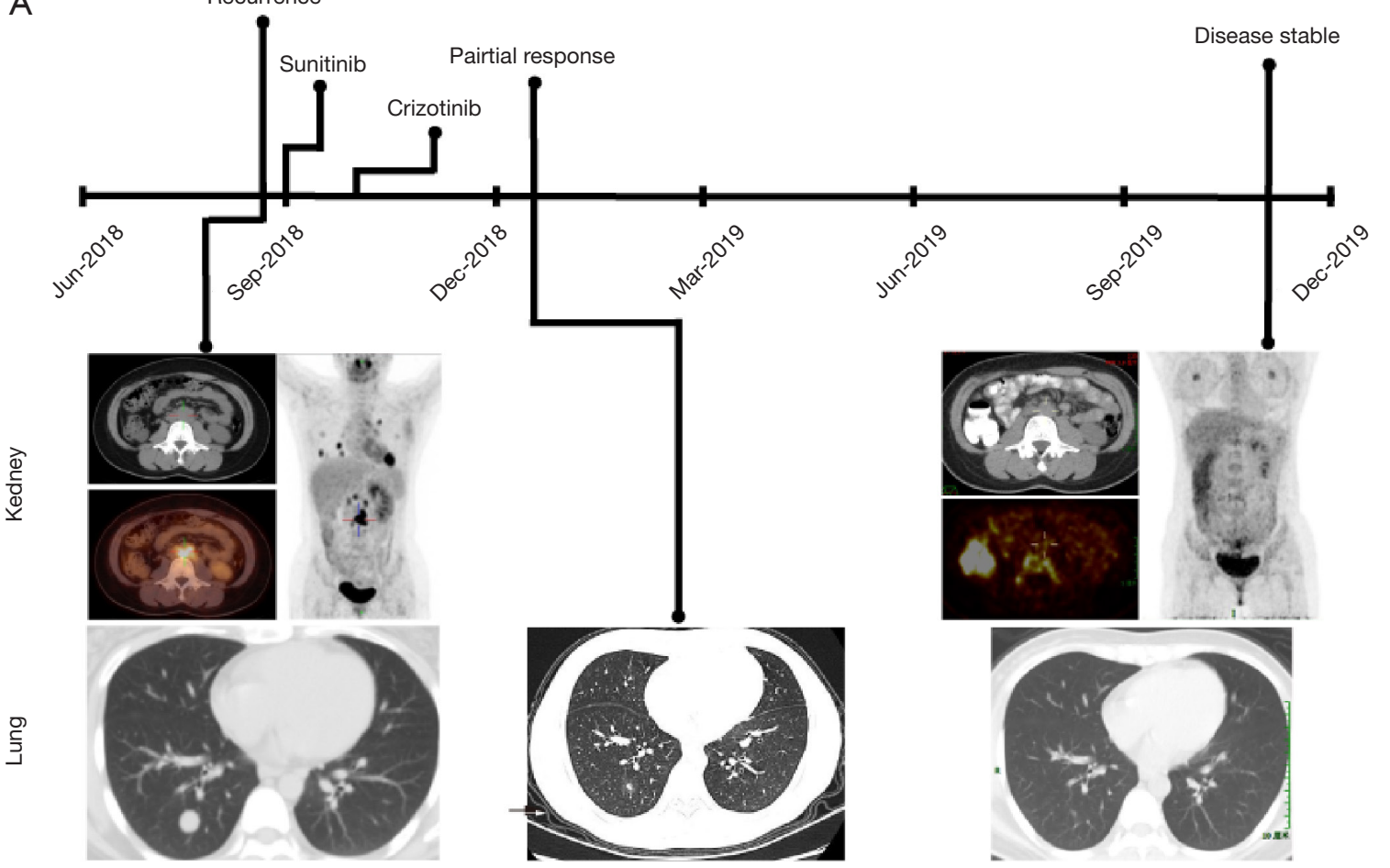

B

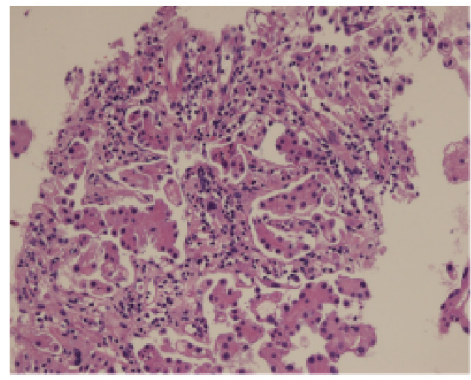

C

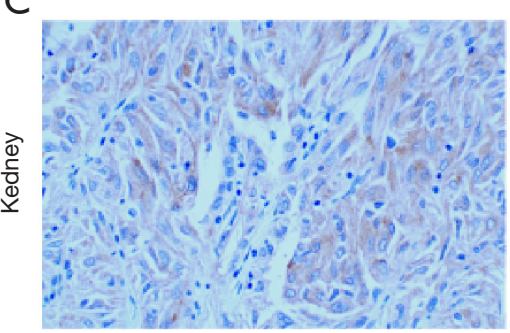

E
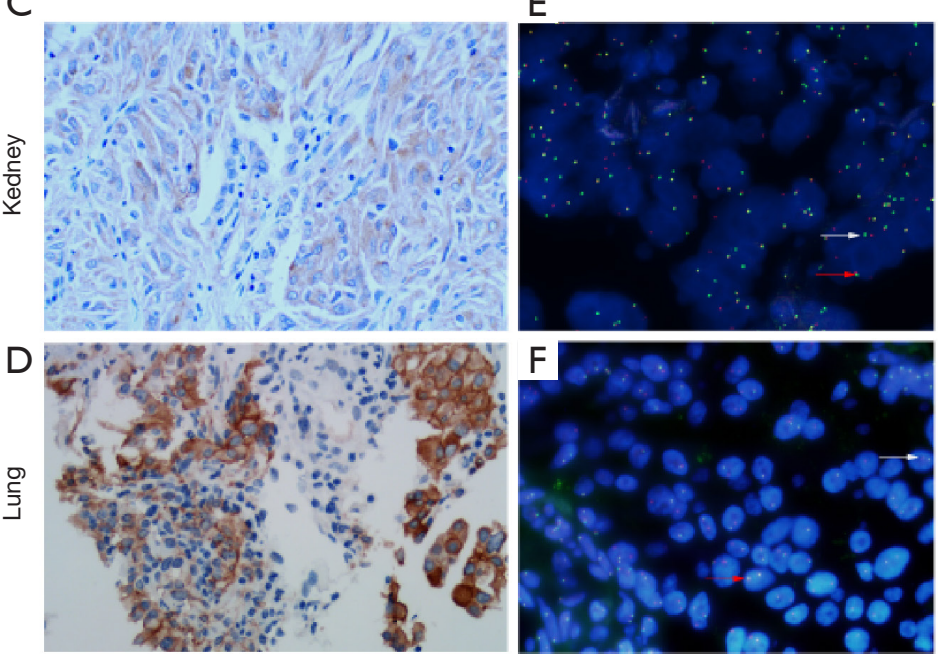

Figure 1 Images and histologic findings during the clinical course. (A) Timeline of patient's treatment process from recurrence in August 2018 to November 2019. The top panel is the timeline, the middle panel displays the images of the renal lesion, and the third panel displays the images of the lung lesions. (B) Histopathological result of the lung lesions in August 2018 (hematoxylin and eosin staining; magnification, $\times 400$ ). (C) IHC for ALK protein expression of the renal lesions: magnification, $\times 400$. (D) IHC for ALK protein expression of the lung lesion: magnification, $\times 400$. (E) FISH analysis with the Vysis LSI ALK dual colour break-apart probe confirmed the presence of ALK rearrangement, the separated red-green signals are indicative of ALK rearrangement (white arrows), while touching red-green signals are not indicative of an ALK rearrangement (red arrows). (F) FISH analysis with the Vysis LSI ALK dual colour break-apart probe confirmed the presence of ALK rearrangement, the separated red-green signals are indicative of ALK rearrangement (white arrows), while touching red-green signals are not indicative of an ALK rearrangement (red arrows). ALK, anaplastic lymphoma kinase. FISH, fluorescence in situ hybridization. FISH, Fluorescence in situ hybridization; RT-PCR, real-time reverse transcription-PCR; IHC, immunohistochemistry. 
Table 1 Clinic and genetic information of ALK-RCC patients

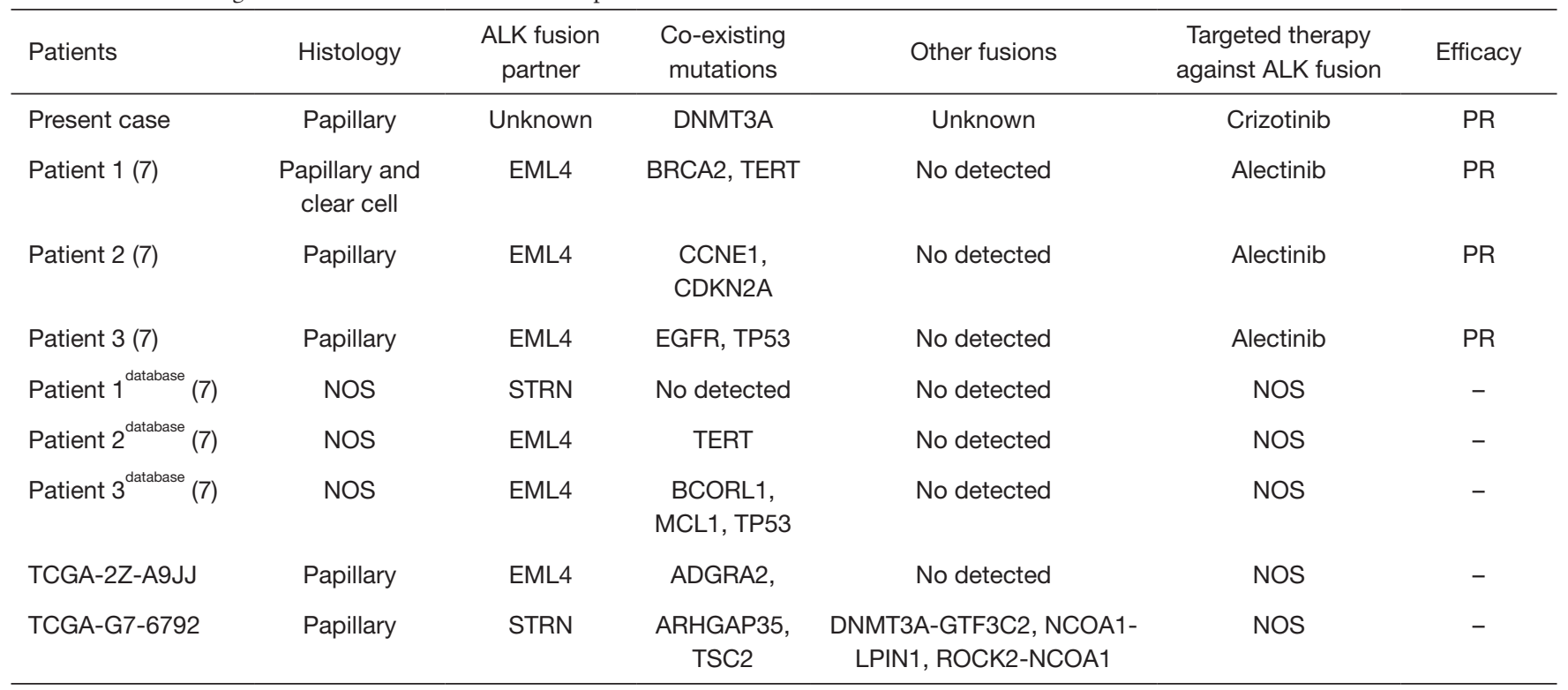

The co-existing mutations and other fusions specifically refer to the cancer gene alterations, and the mutations and fusions of non-cancer genes are not listed. ALK, anaplastic lymphoma kinase; ALK-RCC, ALK-rearranged RCC; PR, partial response; NOS, not otherwise specified.

A

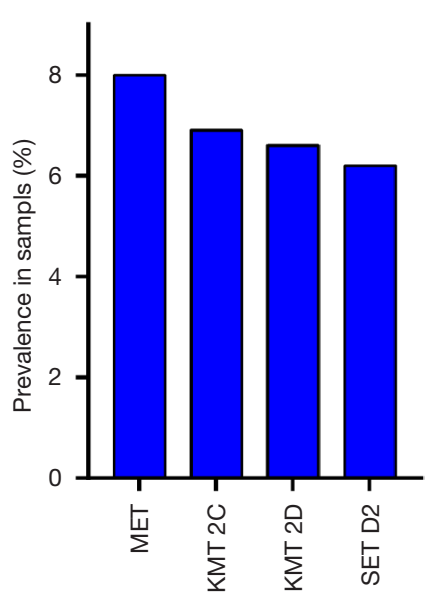

B

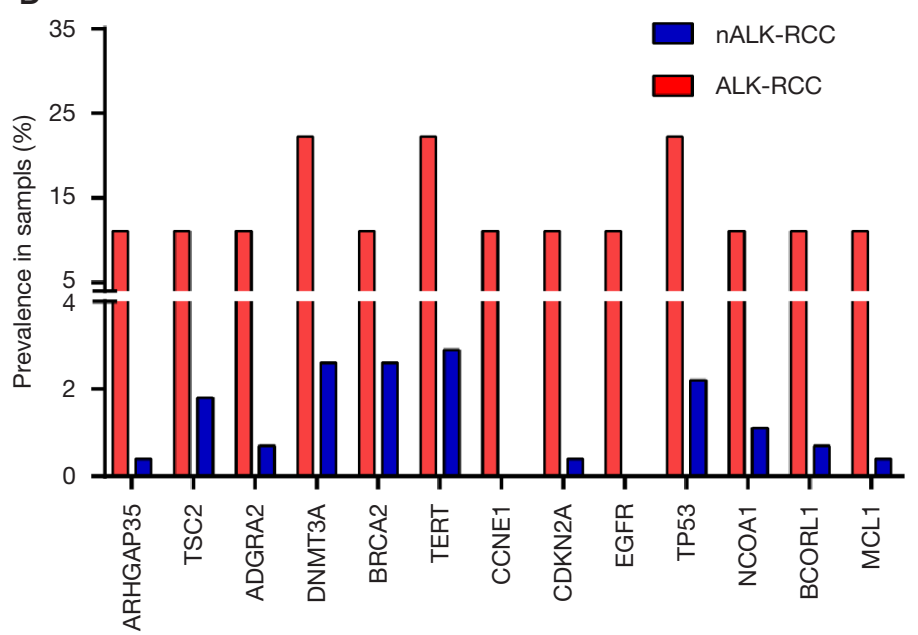

Figure 2 Genetic features of ALK-RCC. (A) The common mutations of cancer genes occurred in nALK-RCC patients. (B) Comparison of ALK-RCC and nALK-RCC in the co-existing cancer gene mutations with ALK fusions. ALK, anaplastic lymphoma kinase; ALK-RCC, ALK-rearranged RCC.

TP53. Although these mutations could be found in nALKRCC, they were expressed at a lower frequency (lower than $3 \%$ ) (Figure $2 B$ ). When compared to previously published cases, these results reveal a different genetic profile of ALKRCC from that of nALK-RCC.
Written consent for all forms of personally identifiable data including biomedical, clinical, and biometric data was obtained from the patient. All procedures performed in studies involving human participants were in accordance with the ethical standards of the institutional and/or 
national research committee(s) and with the Helsinki Declaration (as revised in 2013).

\section{Discussion}

Targeted therapy is at the forefront of malignant tumor treatment. Identification of appropriate patient population with reliable detective methods is the key to targeted therapies. Patients harboring ALK rearrangement are sensitive to ALK inhibitor, such as crizotinib. In our report, the patient was tested with IHC and was diagnosed as ALK positive. In order to further confirm the ALK status, the patient was diagnosed with ALK rearrangement by combining ALK Ventana-D5F3 IHC assay and FISH analysis. Previous studies have also indicated that combinational assay of ALK FISH and IHC methods are highly recommended to accurately select the patients who could potentially benefit from targeted therapy $(18,19)$. Finally, the patient was treated with crizotinib instead of sunitinib.

ALK rearrangement in RCCs is rare and the detection method for lung metastases complicated by renal cell carcinoma has not been reported. Vetana-D5F3 IHC has high sensitivity (100\%) and specificity (98\%) (19) and a large number of cases require rapid screening for the identification of those few NSCLC patients who may benefit from ALK inhibitors. Therefore, IHC is relatively fast and inexpensive, and is perfectly adapted for clinical practice by academics and most community hospitals. In contrast, FISH is the current standard method for detecting ALK rearrangement and is the only test correlated with clinical response because of its use in clinical trials. The combination of IHC assay and FISH analysis can perfectly detect ALK status in our report. However, FISH can't be used to detect ALK fusion partner gene, it is recommended to use other technical platforms for retesting, such as FISH, RT-PCR or NGS.

$A L K$ gene rearrangements encode driver fusion oncoproteins, and ALK tyrosine kinase inhibitors (TKIs) including crizotinib (20), ceritinib (21), alectinib (22), brigatinib (23) and lorlatinib (24) have been developed for patients with ALK-positive NSCLC. The most common adverse drug reactions with ALK tyrosine kinase inhibitors (TKIs), such as alectinib, are stomatitis, interstitial lung disease, weight gain, photosensitivity reaction, and druginduced liver injury (25). In our report, we present a rare ALK-rearranged RCC case. After recurrence, the patient initially received sunitinib treatment before the identification of the ALK rearrangement. According to National Comprehensive Cancer Net-work guidelines, sunitinib is a standard-of-care first-line therapy for advanced RCC patients. However, many patients have inherent resistance to sunitinib and most of the remaining patients eventually demonstrate tumor growth (26,27). In our case, the toxicity brought by the sunitinib was intolerable, and the patient was treated with crizotinib after treatment failure of sunitinib. The patient experienced a partial tumor response and has tolerated crizotinib well. The efficacy of crizotinib has been investigated in a phase II clinical trial, and results demonstrated that crizotinib achieved objective responses and long-lasting disease control in advanced papillary RCC patients with MET mutations or amplification (28). Recently, alectinib was also demonstrated to be effective in treating ALK-RCC (29). Several clinical trials have revealed that alectinib has superior efficacy and lower toxicity in NSCLC when compared with crizotinib (14,30). However, from the perspective of molecular alterations in RCC, ALK alternations are rare, while MET alterations are common occurrence in RCC (31), and so crizotinib is a more potent therapeutic option in RCC with ALK or MET alterations.

A better understanding of the incremental benefit of ALK tyrosine kinase inhibitors (TKIs) in ALK-RCC patient is needed. We performed whole exome sequencing (WES) on the patient to study her genomic features and compared her mutation data with that of nALK-RCC. The most frequent mutations in nALK-RCC were not found in ALK-RCC. This may indicate that ALK fusions were mutually exclusive with these mutations in RCC. In NSCLC, ALK fusion have been reported to be concurrent with TP53, CDKN2A/ $\mathrm{B}$, SETD2, and EGFR mutations (from high frequency to low frequency) (32). Among these, CDKN2A, TP53, and EGFR mutations were also reported to co-exist with ALK fusions in RCC patients (29). However, the concurrent gene alterations, such as SETD2, a histone modifier with tumor suppressor functionality, may be underestimated due to the small number of ALK-RCC patients. While SETD2 was not found in ALK-RCC, we noted that DNMT3A, a DNA methyltransferase, is co-mutated with ALK fusion in two RCC patients, with one being a point-mutation and the other being a fusion mutation. Additionally, TERT promoter was also found to be concurrently mutated with EML4-ALK fusion in two RCC patients (29), and may have clinical implications in cancer via telomerase activation (33). These co-occurring genetic alterations may cooperate with the oncogenic function of ALK in promoting RCC progression and therapy resistance in both the targeted 
therapy-naïve and the acquired resistance setting. However, ALK-RCC genetic differences need further follow-up and large data sample research.

\section{Conclusions}

Our report demonstrated the efficacy of crizotinib in an RCC patient with ALK rearrangement. However, due to the low frequency of ALK alterations in RCC, conducting trails with large amount of cases to investigate the efficacy of crizotinib may be unfeasible. We further discovered a possible differential genomic feature of ALK-RCC, but more genetic data from RCC cases with ALK fusions are needed for further validation.

\section{Acknowledgments}

The authors would like to thank Shanghai Tongshu Biotechnology Co., Ltd. for technical support.

Funding: None.

\section{Footnote}

Reporting Checklist: The authors have completed the CARE reporting checklist. Available at http://dx.doi.org/10.21037/ tau-20-1343

Conflicts of Interest: All authors have completed the ICMJE uniform disclosure form (available at http://dx.doi. org/10.21037/tau-20-1343). The authors have no conflicts of interest to declare.

Ethical Statement: The authors are accountable for all aspects of the work in ensuring that questions related to the accuracy or integrity of any part of the work are appropriately investigated and resolved. Written consent for all forms of personally identifiable data including biomedical, clinical, and biometric data was obtained from the patient. All procedures performed in studies involving human participants were in accordance with the ethical standards of the institutional and/or national research committee(s) and with the Helsinki Declaration (as revised in 2013).

Open Access Statement: This is an Open Access article distributed in accordance with the Creative Commons Attribution-NonCommercial-NoDerivs 4.0 International License (CC BY-NC-ND 4.0), which permits the non- commercial replication and distribution of the article with the strict proviso that no changes or edits are made and the original work is properly cited (including links to both the formal publication through the relevant DOI and the license). See: https://creativecommons.org/licenses/by-nc-nd/4.0/.

\section{References}

1. Ljungberg B, Campbell SC, Choi HY, et al. The epidemiology of renal cell carcinoma. Eur Urol 2011;60:615-21.

2. Hofmann HS, Neef H, Krohe K, et al. Prognostic factors and survival after pulmonary resection of metastatic renal cell carcinoma. Eur Urol 2005;48:77-81; discussion 81-2.

3. Wang L, Cai W, Kong W, et al. Plasma fibrinogen as prognostic predictor in patients with metastatic renal cell carcinoma receiving target therapy. Transl Cancer Res 2018;7:1384-92.

4. Shimada $M$, Fukuda $M$, Fukuda $M$, et al. Adverse renal effects of anaplastic lymphoma kinase inhibitors and the response to alectinib of an ALK+ lung cancer patient with renal dysfunction. Onco Targets Ther 2017;10:3211-4.

5. Sukov WR, Hodge JC, Lohse CM, et al. ALK alterations in adult renal cell carcinoma: frequency, clinicopathologic features and outcome in a large series of consecutively treated patients. Mod Pathol 2012;25:1516-25.

6. Soda M, Choi YL, Enomoto M, et al. Identification of the transforming EML4-ALK fusion gene in non-small-cell lung cancer. Nature 2007;448:561-6.

7. Shan L, Jiang P, Xu F, et al. BIRC6-ALK, a Novel Fusion Gene in ALK Break-Apart FISH-Negative Lung Adenocarcinoma, Responds to Crizotinib. J Thorac Oncol 2015;10:e37-9.

8. Rikova K, Guo A, Zeng Q, et al. Global survey of phosphotyrosine signaling identifies oncogenic kinases in lung cancer. Cell 2007;131:1190-203.

9. Kim RN, Choi YL, Lee MS, et al. SEC31A-ALK Fusion Gene in Lung Adenocarcinoma. Cancer Res Treat 2016;48:398-402.

10. Ou SH, Klempner SJ, Greenbowe JR, et al. Identification of a novel HIP1-ALK fusion variant in Non-Small-Cell Lung Cancer (NSCLC) and discovery of ALK I1171 (I1171N/S) mutations in two ALK-rearranged NSCLC patients with resistance to Alectinib. J Thorac Oncol 2014;9:1821-5.

11. Fang DD, Zhang B, Gu Q, et al. HIP1-ALK, a novel ALK fusion variant that responds to crizotinib. J Thorac Oncol 2014;9:285-94. 
12. Iyevleva AG, Raskin GA, Tiurin VI, et al. Novel ALK fusion partners in lung cancer. Cancer Lett 2015;362:116-21.

13. Togashi Y, Soda M, Sakata S, et al. KLC1-ALK: a novel fusion in lung cancer identified using a formalin-fixed paraffin-embedded tissue only. PLoS One 2012;7:e31323.

14. Peters S, Camidge DR, Shaw AT, et al. Alectinib versus Crizotinib in Untreated ALK-Positive Non-Small-Cell Lung Cancer. N Engl J Med 2017;377:829-38.

15. Wu YL, Lu S, Lu Y, et al. Results of PROFILE 1029, a Phase III Comparison of First-Line Crizotinib versus Chemotherapy in East Asian Patients with ALK-Positive Advanced Non-Small Cell Lung Cancer. J Thorac Oncol 2018;13:1539-48.

16. Noonan SA, Camidge DR. PROFILE 1014: lessons for the new era of lung cancer clinical research. Transl Lung Cancer Res 2015;4:642-8.

17. Yi ES, Boland JM, Maleszewski JJ, et al. Correlation of IHC and FISH for ALK gene rearrangement in non-small cell lung carcinoma: IHC score algorithm for FISH. J Thorac Oncol 2011;6:459-65.

18. Li W, Zhang J, Guo L, et al. Combinational Analysis of FISH and Immunohistochemistry Reveals Rare Genomic Events in ALK Fusion Patterns in NSCLC that Responds to Crizotinib Treatment. J Thorac Oncol 2017;12:94-101.

19. Conklin CM, Craddock KJ, Have C, et al. Immunohistochemistry is a reliable screening tool for identification of ALK rearrangement in non-small-cell lung carcinoma and is antibody dependent. J Thorac Oncol 2013;8:45-51.

20. Shaw AT, Kim DW, Nakagawa K, et al. Crizotinib versus chemotherapy in advanced ALK-positive lung cancer. N Engl J Med 2013;368:2385-94.

21. Shaw AT, Kim DW, Mehra R, et al. Ceritinib in ALKrearranged non-small-cell lung cancer. N Engl J Med 2014;370:1189-97.

22. Ou SH, Ahn JS, De Petris L, et al. Alectinib in Crizotinib-Refractory ALK-Rearranged Non-SmallCell Lung Cancer: A Phase II Global Study. J Clin Oncol 2016;34:661-8.

23. Kim DW, Tiseo M, Ahn MJ, et al. Brigatinib in Patients With Crizotinib-Refractory Anaplastic Lymphoma Kinase-Positive Non-Small-Cell Lung Cancer: A Randomized, Multicenter Phase II Trial. J Clin Oncol 2017;35:2490-2498.

24. Shaw AT, Felip E, Bauer TM, et al. Lorlatinib in non- small-cell lung cancer with ALK or ROS1 rearrangement: an international, multicentre, open-label, single-arm firstin-man phase 1 trial. Lancet Oncol 2017;18:1590-9.

25. Ramachandran P, Morcus R, Tahir M, et al. Alectinib (Alecensa)-induced reversible grade IV nephrotoxicity: a case report and review of the literature. J Med Case Rep 2018;12:303.

26. Motzer RJ, Penkov K, Haanen J, et al. Avelumab plus Axitinib versus Sunitinib for Advanced Renal-Cell Carcinoma. N Engl J Med 2019;380:1103-15.

27. Zhou L, Liu XD, Sun M, et al. Targeting MET and AXL overcomes resistance to sunitinib therapy in renal cell carcinoma. Oncogene 2016;35:2687-97.

28. Schöffski P, Wozniak A, Escudier B, et al. Crizotinib achieves long-lasting disease control in advanced papillary renal-cell carcinoma type 1 patients with MET mutations or amplification. EORTC 90101 CREATE trial. Eur J Cancer 2017;87:147-63.

29. Pal SK, Bergerot P, Dizman N, et al. Responses to Alectinib in ALK-rearranged Papillary Renal Cell Carcinoma. Eur Urol 2018;74:124-8.

30. Hida T, Nokihara H, Kondo M, et al. Alectinib versus crizotinib in patients with ALK-positive non-small-cell lung cancer (J-ALEX): an open-label, randomised phase 3 trial. Lancet 2017;390:29-39.

31. Choueiri TK, Escudier B, Powles T, et al. Cabozantinib versus Everolimus in Advanced Renal-Cell Carcinoma. N Engl J Med 2015;373:1814-23.

32. Wu W, Haderk F, Bivona TG. Non-Canonical Thinking for Targeting ALK-Fusion Onco-Proteins in Lung Cancer. Cancers (Basel) 2017;9:164.

33. Leão R, Apolónio JD, Lee D, et al. Mechanisms of human telomerase reverse transcriptase (hTERT) regulation: clinical impacts in cancer. J Biomed Sci 2018;25:22.

(English Language Editor: L. Grey)

(Quality Control Editor: J. Gray)

Cite this article as: Zhou S, Sun G, Wang J, Zhang H. Anaplastic lymphoma kinase (ALK) rearrangement in adult renal cell carcinoma with lung metastasis: a case report and literature review. Transl Androl Urol 2020;9(6):2855-2861. doi: $10.21037 /$ tau-20-1343 


\section{Supplementary}
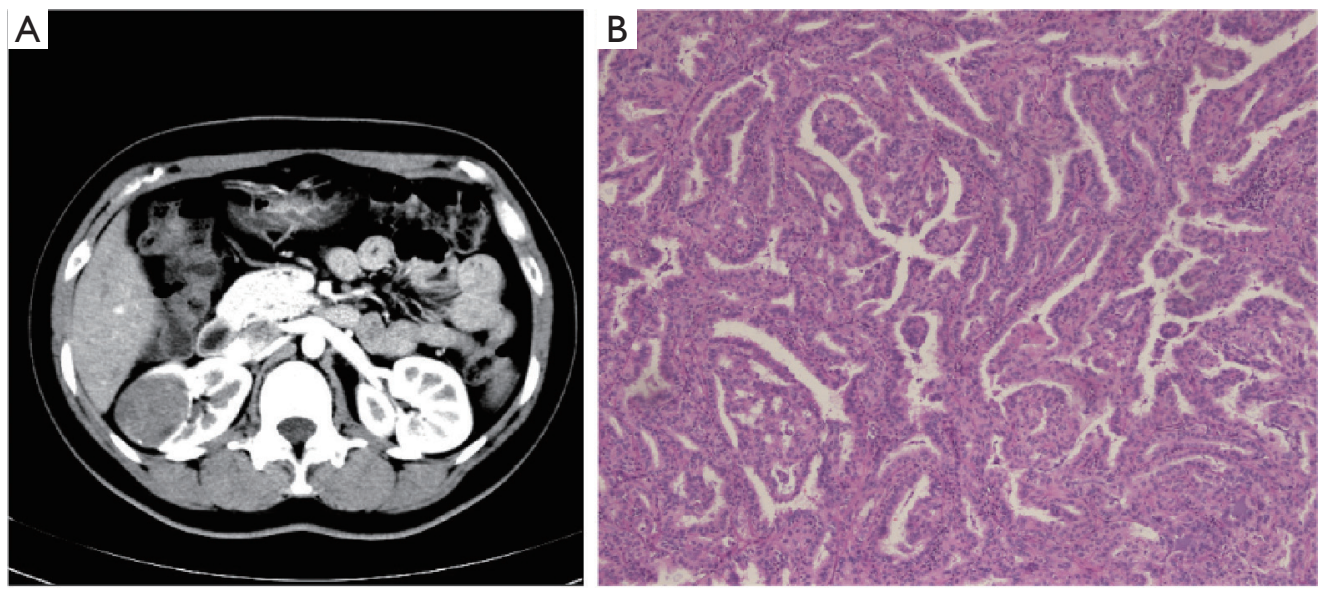

Jul-2011

Figure S1 Representative CT image and histopathological result of a renal lesion in July 2011. (A) Abdominal contrast-enhanced CT scan of the renal lesion (July 2011). (B) Histopathological result of the renal lesion (hematoxylin and eosin staining; magnification, $\times 400$ ). 